\title{
Drug survival and reasons for discontinuation of the first course of biological therapy in 301 juvenile idiopathic arthritis patients
}

\author{
M. Romano1, I. Pontikaki', M. Gattinara1', I. Ardoino², C. Donati', \\ P. Boracchi' ${ }^{2}$, P.L. Meroni', V. Gerloni ${ }^{1}$ \\ 'Istituto Ortopedico Gaetano Pini, Cattedra e Dipartimento di Reumatologia, Università degli Studi di Milano; \\ 'Unità di Statistica Medica e Biometria 'G.A. Maccacaro', Dipartimento di Scienze Cliniche e di Comunità, \\ Università degli Studi di Milano, Italy
}

\section{SUMMARY}

The objective of this study was to determine long-term effectiveness and safety of $1^{\text {st }}$ biological treatment (BT) in a cohort of 301 juvenile idiopathic arthritis (JIA) patients (pts), non-responders to disease-modifying antirheumatic drugs (DMARDs), in terms of drug survival (continuation rate on therapy) and to identify the baseline predictors of treatment discontinuation.

Each JIA pt enrolled in BT is prospectively assessed at the start of treatment and then every 2 months for the evaluation of safety and efficacy according to ACR-Pedi30 criteria. All clinical charts of pts who started a BT between November 1999 and July 2010 have been reviewed. Survival analysis methods suitable for competing risks were used to study time to drug discontinuation due to disease control (defined according to Wallace criteria) or failure [adverse event (AE), lack of efficacy (LaE) or loss of efficacy (LoE) according ACR-Pedi30]. A number of 301 JIA pts, non-responders or intolerant to DMARDs and treated with one or more cycles of BT, were identified. Median disease duration, from onset to the beginning of $1^{\text {st }}$ BT, was 7.8 years (interquartil range 2.21-15.1). In total, there were $2941^{\text {st }}$ corses with anti-TNF agents, 5 with abatacept and 2 with anakinra. A number of 298 pts were included in the analysis for drug discontinuation (3 pts with no follow-up data after their first dose of BT were excluded). The median follow-up on treatment, before discontinuation due to every cause, was 53.7 months (range 0.45-124.45). One hundred and sixty-five pts discontinued BT: 27 due to disease control, 135 because of failure ( $78 \mathrm{AEs}, 12 \mathrm{LaE}$ and $45 \mathrm{LoE}$ ), 3 pts temporarily stopped for pregnancy. Among 135 pts who discontinued for failure, 117 switched to a $2^{\text {nd }}$ BT. Among 27 pts who discontinued due to remission, 13 pts restarted on BT for relapse of disease activity ( 10 pts restarted with the same BT, 3 switched to a different one). Predictors of discontinuation due to $\mathrm{AE}$ were female gender $(\mathrm{P}=0.01)$ and longer disease duration $(\mathrm{P}=0.02)$. Predictors of discontinuation due to $\mathrm{LaE}$ or $\mathrm{LoE}$ were systemic onset and polyarthritis FR positive (vs other JIA subtypes) $(\mathrm{P}<0.05)$ and use of $\mathrm{mAb}$-anti-TNF (vs sTNFR) $(\mathrm{P}=0.02)$. Predictors of discontinuation due to inactive disease were male gender and shorter disease duration $(\mathrm{P}<0.05)$.

Although only few pts discontinued BT due to a complete and persistent disease control, the majority of them remained on BT for a long time, suggesting that in our cohort of JIA pts, affected by a severe long lasting refractory disease, BT was globally well tolerate and efficacious in controlling the disease.

Key words: Drug survival, Biological therapy, Juvenile idiopathic arthritis.

Reumatismo, 2013; 65 (6): 278-285

$\overline{\text { Corresponding author: }}$ Micol Romano Istituto Ortopedico Gaetano Pini Cattedra e Dipartimento di Reumatologia Università degli Studi di Milano P.zza Cardinal Ferrari, 1 - 20122 Milano, Italy E-mail: micol.romano@unimi.it

\section{INTRODUCTION}

he introduction of TNF-blocking agents since 2000 has tremendously changed the treatment of juvenile idiopathic arthritis (JIA). From randomized controlled trials there is evidence that TNF-blocking agents are efficacious and safe, but data on their long-term expected and unexpected effects remain relatively scarce.

Longer follow-up of TNF-blocking agents is necessary in order to report the occurrence of adverse events (AE). To this aim, an observational study is an appropriate design (1).

There have been few reports of biological 
treatment $(\mathrm{BT})$ discontinuation rates and factors associated with discontinuation (24). The aim of this study is to collect longterm outcome data on children receiving biological agents for JIA in terms of drug survival and to explore the reasons for biological therapy discontinuation.

\section{MATERIALS AND METHODS}

Since November 1999 to July 2010, all JIA patients (pts) who started for the first time a BT at Pediatric Unit of Rheumatology Department of Gaetano Pini Institute, University of Milan, have been included in this prospective cohort study.

At baseline and at each visit, the following assessments were performed: the number and site of active joints, the number and site of limited joints, erythrocyte sedimentation rate and/or C-reactive protein, patient visual analogue scales (VAS 0-100 mm) for general health and for pain, physician VAS for disease activity and the CHAQ Disability Index. Treatment response to methotrexate (MTX) and previous disease-modifying antirheumatic drugs (DMARDs), and the eligibility for BT, was judged according to the ACR-Pedi30 response criteria (5). After starting the treatment, follow-up data were collected every 2 months. AE data were collected as part of monitoring.

Discontinuation was defined as cessation of the drug because of disease control according to Wallace criteria [inactive disease (ID) (6) or clinical remission on medication (CRM)], or failure. Failure was defined by AEs or inefficacy according to ACR-Pedi30, inefficacy was defined as: lack of efficacy (LaE), after a minimum period on therapy of at least 6 weeks, or loss of efficacy (LoE) after a variable period of successful treatment.

\section{STATISTICAL ANALYSIS}

Time to discontinuation was defined according to the date of stop/switched or to the last follow-up on therapy. Statistical analysis was performed by methods suit- able for the presence of competing events in survival analysis. In the competing risks setup, in fact, patients during the follow-up are exposed to the risk of stopping/switching BT for different causes, also before achieving CRM. Crude cumulative incidences (CCI) were estimated using a proper non-parametric estimator in the competing events framework and were compared by the Gray test (7). An extension of Cox proportional hazards models which the risk of competing events is taken into account was used to estimate the specific hazard for CCI with $95 \%$ CI (8).

Beside kind of BT, and concomitant treatment with DMARDs the following predictors were considered in the statistical analysis: gender, ILAR category, age at symptom onset, age at and disease duration before starting BT.

In the multivariable analysis, all variables above mentioned were firstly included. In the final model, gender and kind of BT were always retained, together with other predictors only if they were statistically significant $(\mathrm{P}<0.05)$ or if they showed moderate evidence of association $(\mathrm{P} \leq 0.1)$ with the outcome of interest.

\section{RESULTS}

On the whole 301 JIA pts treated with one or more courses of biological drugs were enrolled. Main demographic and baseline characteristics are summarized in Table I. The majority of them $(57.8 \%)$ were initially treated with etanercept (174). In total 294 pts were treated with anti-TNF agents as the first course of BT, 5 with abatacept and 2 with anakinra.

In total 580 different courses of biological agents were administered to 301 pts. The median number of treatments for patient was 1 (range 1-8), ranging from 1 in persistent oligoarticular JIA to 2 and 1.5 in systemic onset JIA (so-JIA) and psoriatic arthritis respectively.

More than half of treatments $(323,55.7 \%)$, were administered in monotherapy, the remaining were given in combination with one or more DMARDs. MTX (268) was 
Table I - Demographic and baseline characteristics for each juvenile idiopathic arthritis subtype.

\begin{tabular}{|c|c|c|c|c|c|c|}
\hline JIA subtype & $\begin{array}{l}\text { Gender F } \\
(\%)\end{array}$ & \begin{tabular}{|l|} 
Uveitis \\
(\%)
\end{tabular} & $\begin{array}{l}\text { Onset age (years) } \\
\text { median ( } 1^{\text {st }} \text { and } 3^{\text {rd }} \\
\text { quartiles) }\end{array}$ & \begin{tabular}{|l|} 
Age of \\
initiation of BT \\
(years) median \\
(1 ${\text { (st } \text { and } 3^{\text {rd }}}^{\text {quartiles) }}$ \\
\end{tabular} & 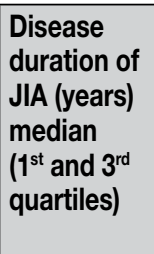 & \begin{tabular}{|l|} 
Treatment \\
duration at \\
last follow- \\
up (months) \\
median \\
(15t and $3^{\text {rd }}$ \\
quartiles)
\end{tabular} \\
\hline $\begin{array}{l}\text { Systemic arthritis } \\
50(16.6 \%)\end{array}$ & \begin{tabular}{|l|}
31 \\
$(62.0 \%)$
\end{tabular} & \begin{tabular}{|l|}
0 \\
$(0 \%)$
\end{tabular} & \begin{tabular}{|l|}
5.8 \\
$(3.98-12-3)$
\end{tabular} & $\begin{array}{l}16.7 \\
(10.66-23.95)\end{array}$ & \begin{tabular}{|l|}
8.3 \\
$(3.03-16.07)$
\end{tabular} & \begin{tabular}{|l|}
12.6 \\
$(5.14-47.10)$
\end{tabular} \\
\hline $\begin{array}{l}\text { Persistent } \\
\text { oligoarticular } \\
50(16.6 \%)\end{array}$ & $\begin{array}{l}35 \\
(70.0 \%)\end{array}$ & \begin{tabular}{|l|}
22 \\
$(44.0 \%)$
\end{tabular} & $\begin{array}{l}3.0 \\
(1.99-6.42)\end{array}$ & \begin{tabular}{|l|}
12.4 \\
$(6.83-17.95)$
\end{tabular} & $\begin{array}{l}7.5 \\
(3.35-11.38)\end{array}$ & \begin{tabular}{|l|}
23.7 \\
$(12.23-43.54)$
\end{tabular} \\
\hline $\begin{array}{l}\text { Extended } \\
\text { oligoarticular } \\
87(28.9 \%)\end{array}$ & \begin{tabular}{|l|}
73 \\
$(83.9 \%)$
\end{tabular} & \begin{tabular}{|l|}
24 \\
$(27.6 \%)$
\end{tabular} & $\begin{array}{l}2.7 \\
(1.57-6.44)\end{array}$ & \begin{tabular}{|l|}
13.5 \\
$(8.74-21.28)$
\end{tabular} & $\begin{array}{l}8.8 \\
(4.17-17.60)\end{array}$ & \begin{tabular}{|l|}
25.3 \\
$(12.38-43.36)$
\end{tabular} \\
\hline $\begin{array}{l}\text { RF negative } \\
\text { poliarticular } \\
58(19.3 \%) \\
\end{array}$ & \begin{tabular}{|l|}
42 \\
$(72.4 \%)$
\end{tabular} & $\begin{array}{l}7 \\
(12.1 \%)\end{array}$ & \begin{tabular}{|l|}
5.9 \\
$(2.72-9.60)$
\end{tabular} & \begin{tabular}{|l|}
13.8 \\
$(8.46-19.18)$ \\
\end{tabular} & $\begin{array}{l}7.5 \\
(1.31-11.55)\end{array}$ & \begin{tabular}{|l|}
23.7 \\
$(11.66-50.96)$
\end{tabular} \\
\hline $\begin{array}{l}\text { RF positive } \\
\text { poliarticular } \\
28(9.3 \%) \\
\end{array}$ & \begin{tabular}{|l|}
23 \\
$(82.1 \%)$
\end{tabular} & \begin{tabular}{|l|}
0 \\
$(0 \%)$
\end{tabular} & $\begin{array}{l}11.9 \\
(10.02-14.5)\end{array}$ & \begin{tabular}{|l|}
17.4 \\
$(14.76-20.11)$
\end{tabular} & \begin{tabular}{|l|}
5.1 \\
$(0.71-9.89)$
\end{tabular} & \begin{tabular}{|l|}
19.1 \\
$(10.28-49.71)$
\end{tabular} \\
\hline $\begin{array}{l}\text { Entesitis related } \\
\text { arthritis } \\
18(6.0 \%)\end{array}$ & $\begin{array}{l}7 \\
(38.9 \%)\end{array}$ & $\begin{array}{l}1 \\
(5.6 \%)\end{array}$ & $\begin{array}{l}11.7 \\
(9.54-13.10)\end{array}$ & \begin{tabular}{|l|}
18.5 \\
$(14.88-23.82)$
\end{tabular} & $\begin{array}{l}7.3 \\
(2.83-10.77)\end{array}$ & $\begin{array}{l}32.7 \\
(12.85-60.7)\end{array}$ \\
\hline $\begin{array}{l}\text { Psoriatic arthritis } \\
10(3.3 \%)\end{array}$ & \begin{tabular}{|l|}
6 \\
$(6.0 \%)$
\end{tabular} & \begin{tabular}{|l|}
2 \\
$(22.2 \%)$ \\
\end{tabular} & \begin{tabular}{|l|}
8.2 \\
$(3.18-9.99)$ \\
\end{tabular} & \begin{tabular}{|l|}
23.8 \\
$(16.98-30.74)$
\end{tabular} & \begin{tabular}{|l|}
14.5 \\
$(8.03-22.62)$ \\
\end{tabular} & \begin{tabular}{|l|}
37.4 \\
$(22.17-47.18)$ \\
\end{tabular} \\
\hline $\begin{array}{l}\text { Total } \\
301\end{array}$ & \begin{tabular}{|l}
218 \\
$(72.4 \%)$ \\
\end{tabular} & \begin{tabular}{|l}
56 \\
$(18.6 \%)$ \\
\end{tabular} & \begin{tabular}{|l}
5.3 \\
$(2.37-11.11)$ \\
\end{tabular} & \begin{tabular}{|l|}
15.1 \\
$(9.39-21.07)$ \\
\end{tabular} & \begin{tabular}{|l}
7.8 \\
$(2.21-15.1)$ \\
\end{tabular} & \begin{tabular}{|l|}
24.0 \\
$(10.84-48.00)$ \\
\end{tabular} \\
\hline
\end{tabular}

JIA, juvenile idiopathic arthritis; BT, biological treatment.

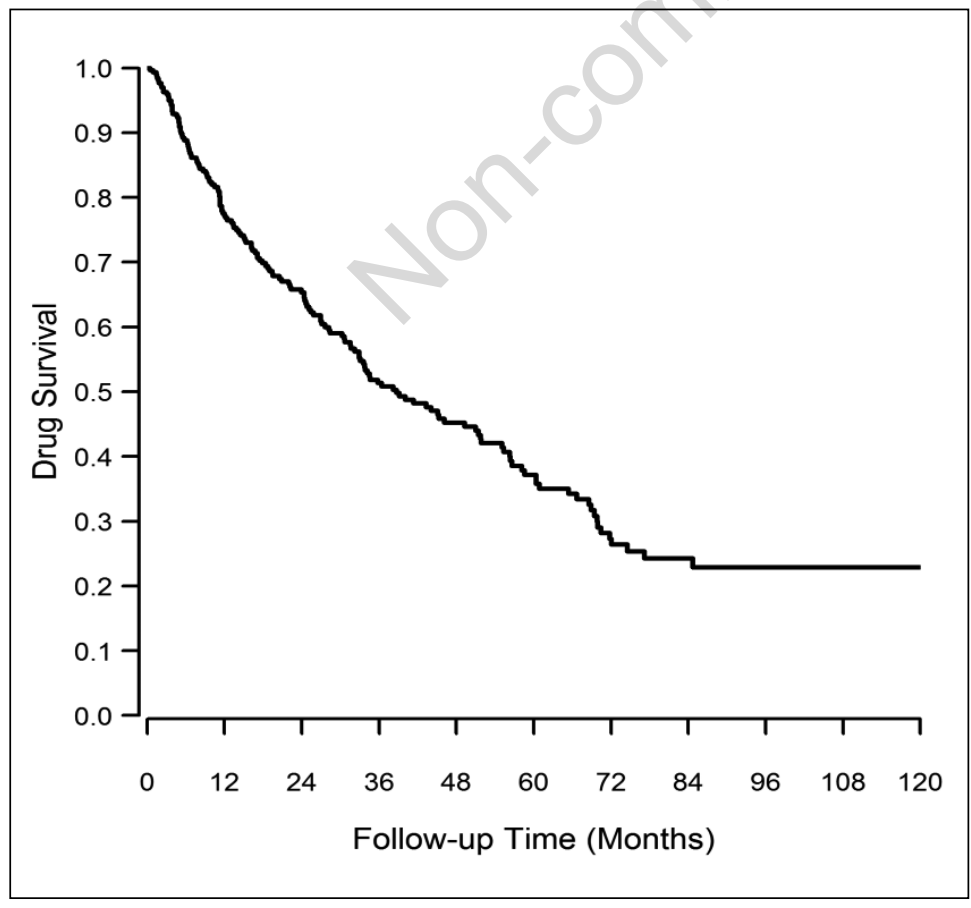

Figure 1 - Kaplan-Meier survival analysis of biological therapy. the most frequently concomitant treatment, 43 BT were associated with leflunomide, 39 with cyclosporin, 25 with sulfasalazine, 21 with $\mathrm{OH}$-chloroquine, 12 with azathioprine and 4 with gold salt.

Causes of discontinuation of the $1^{\text {st }}$ biological treatment and follow-up after discontinuation

All 301 scrutinized patients, but 3 with no available follow-up data after their first dose of BT, were included in the analysis for drug discontinuation. The median follow-up time on treatment, as estimated by Shemper et al. (9) was about 53.7 months (range 0.45-124.45). Figure 1 shows the Kaplan-Meier analysis.

In total 165/298 pts discontinued the therapy (Table II):

- 135 discontinued for failure, in particular:

1) 78 for AEs (CCI 34.58\%),

2) 12 for $\mathrm{LaE}$ (CCI $4.05 \%$ ),

3) 45 for $\operatorname{LoE}$ (CCI 21.67\%); 
Table II - Causes of discontinuation of $1^{\text {st }}$ biological agent and follow-up.

\begin{tabular}{|c|c|c|c|c|c|c|c|c|c|c|}
\hline & \multicolumn{5}{|c|}{ Drug } & \multicolumn{3}{|c|}{ Follow-up } & \multirow[t]{2}{*}{ Total } \\
\hline & & 172 ETA & 83 INFL & 36 ADA & 2 ANA & $5 \mathrm{ABA}$ & Stop & Restart & Switch & \\
\hline Causes & Follow-up & & & & & & & & & \\
\hline \multirow{4}{*}{ AEs } & Stop biol. & 9 & 2 & 1 & & & 12 & & & \\
\hline & Restarted & 1 & 1 & 0 & & & & 2 & & \\
\hline & Switched & 30 & 29 & 4 & 1 & & & & 64 & \\
\hline & Total AEs & 40 & 32 & 5 & 1 & & & & & 78 \\
\hline \multirow{4}{*}{$\mathrm{LaE}$} & Stop biol. & 0 & 0 & 0 & & & 0 & & & \\
\hline & Restarted & 0 & 0 & 0 & & & & 0 & & \\
\hline & Switched & 4 & 4 & 3 & & 1 & & & 12 & \\
\hline & Total LaE & 4 & 4 & 3 & & & & & & 12 \\
\hline \multirow{4}{*}{ LoE } & Stop biol. & 1 & 1 & 0 & & & 2 & & & \\
\hline & Restarted & 2 & 0 & 0 & & & & 2 & & \\
\hline & Switched & 16 & 20 & 4 & & 1 & & & 41 & 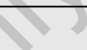 \\
\hline & Total LoE & 19 & 21 & 4 & & & & & & 45 \\
\hline \multirow{4}{*}{ ID } & Stop biol. & 7 & 4 & 3 & & & 14 & & 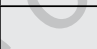 & \\
\hline & Restarted & 8 & 1 & 1 & & & & 10 & 0 & \\
\hline & Switched & 3 & 0 & 0 & & & & 0 & 3 & \\
\hline & Total ID & 18 & 5 & 4 & & & 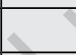 & 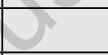 & & 27 \\
\hline \multirow{4}{*}{ Pregnancy } & Stop biol. & 0 & 0 & 0 & & & 0 & & & \\
\hline & Restarted & 1 & 2 & 0 & & & $O$ & 3 & & \\
\hline & Switched & 0 & 0 & 0 & & ) & & & 0 & \\
\hline & \begin{tabular}{|l|} 
Total \\
pregnancy
\end{tabular} & 1 & 2 & & & & & & & 3 \\
\hline \multicolumn{2}{|l|}{\begin{tabular}{|l|} 
Total 165 \\
\end{tabular}} & 82 & 64 & 16 & 1 & 2 & 28 & 17 & 120 & 165 \\
\hline
\end{tabular}

ETA, etanercept; INFL, infliximab; ADA, adalimumab; ANA, anakinra; ABA, abatacept; AEs, adverse events; LaE, lack of efficacy; LoE, loss of efficacy; ID, inactive disease.

- 27 (CCI 14.51\%) discontinued for ID, after reaching CRM, but among these, 13 restarted on a $\mathrm{BT}$, for relapse of disease activity, after a median period free from biological drug of 6.6 months (range 2.428.6);

- 3 pts (CCI $2.3 \%$ ) temporarily stopped for pregnancy.

The majority of pts who suspended the $1^{\text {st }}$ biological approach for any reason $(120 / 165)$, switched to a $2^{\text {nd }}$ one (117 anti-

TNF and 3 non-anti-TNF). In details:

1) 64 out of the 78 pts who discontinued for AEs (12 of them after reaching CRM);

2) 53 out of the 57 pts who discontinued for failure, either for LoE 41 pts ( 6 after CRM) or for LaE 12 pts;

3) 3 pts out of 27 after stopping for ID, relapsed and switched to a $2^{\text {nd }}$ different biological drug.

Seventeen pts discontinued for different reasons but then restarted with the same biological treatment ( 3 pts stopped during pregnancy and restarted after delivery, 10 pts discontinued for ID but then relapsed and restarted). Twenty-eight pts definitively stopped BT, 14 after failure (12 AEs, $2 \mathrm{LoE}$ ) and 14 after reaching the state of CRM. The probability of discontinuation for ID and for the other causes is shown in Figure 2.

\section{Discontinuation due to adverse events}

Considering all first biological treatments, out of our 298 evaluated pts (during a global exposure to study drug of $800.13 \mathrm{pt} / \mathrm{yrs}$ ), 78 discontinued due to an $\mathrm{AE}$ after a median period of therapy of 14.7 months (range 0.5-70.0). The rate of AEs was 0.097 AEs/ $\mathrm{pt} / \mathrm{yrs}$ that means one withdrawal for $\mathrm{AE}$ every $10.27 \mathrm{pt} /$ years.

Among the 78 pts who failed the treatment for AEs, 62 were females: the rate of AEs 


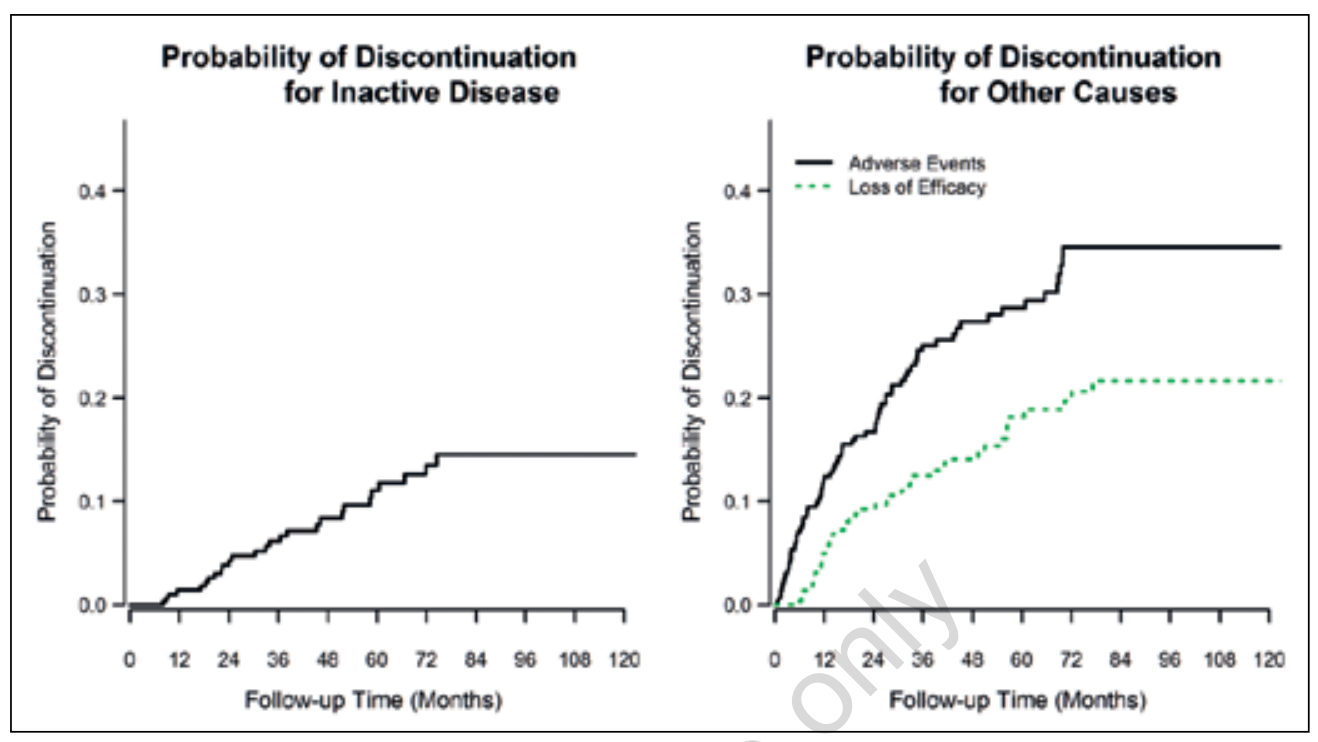

Figure 2 - Treatment discontinuation due to inactive disease, adverse events and loss of efficacy.

Table III - Reported adverse events during biological treatment.

\begin{tabular}{|l|l|}
\hline AE leading to withdrawal & \#TOT \\
\hline Infusion reaction & 23 \\
\hline Behavioral disorders & 12 \\
\hline New onset/relapse/worsening of uveitis & 12 \\
\hline Dermatological manifestations & 8 \\
\hline Inflammatory bowel disease & 7 \\
\hline $\begin{array}{l}\text { Hematological manifestation (leukopenia, } \\
\text { thrombocytopenia, anemia one case each) }\end{array}$ & 3 \\
\hline $\begin{array}{l}\text { Neurological manifestation (one headache, } 2 \\
\text { suspected demyelinating diseases) }\end{array}$ & 3 \\
\hline Autoimmunity/lupus-like & 2 \\
\hline Infections (one leading to MAS) & 2 \\
\hline Ipertension & 2 \\
\hline Injection site reaction & 2 \\
\hline Macrohematuria & 1 \\
\hline Menorrhagia & 1 \\
\hline Total & 78 \\
\hline
\end{tabular}

$\mathrm{AE}$, adverse event; MAS, macrophage-activation syndrome.

in female was $0.11 \mathrm{AEs} / \mathrm{pt} / \mathrm{yrs}$ vs 0.07 in male, that means one withdrawal for $\mathrm{AE}$ every $9.0 \mathrm{pt} / \mathrm{yrs}$ in female $v s$ every $15.1 \mathrm{pt} /$ yrs in male population.

Among the 78 pts who failed the treatment for AEs, 15 were soJIA, and 63 were non-soJIA pts: the rate of AEs in soJIA pts was $0.13 \mathrm{AEs} / \mathrm{pt} / \mathrm{yrs}$ vs 0.09 in non-soJIA, that means one withdrawal for AE every
$7.9 \mathrm{pt} / \mathrm{yrs}$ in soJIA $v s$ every $10.8 \mathrm{pt} / \mathrm{yrs}$ in non-so-JIA population. soJIA suspended for AEs after a median period of therapy of 5.2 months (range 0.5-35.8), non-soJIA suspended for AEs after a median period of therapy of 19.4 months (range 0.9-70.0). According to the disease duration, we considered 2 groups of pts: group I pts with a disease duration $<5$ yrs, group II pts with disease duration longer than 5 yrs. Pts who failed for AEs were respectively 18 out of 108 and 60 out of 193. The rate of AEs was respectively 0.06 vs $0.12 \mathrm{AEs} / \mathrm{pt} / \mathrm{yrs}$ [that means one withdrawal for AE every $15.9 \mathrm{vs}$ $8.6 \mathrm{pt} / \mathrm{yrs}$ respectively].

The only predictor entered in the final multivariable model, beside gender and kind of BT was disease duration before starting treatment (HR for 5 yrs increase 1.17, $\mathrm{P}=0.02$ ) (Table III).

\section{Discontinuation due to lack/loss of effi- cacy}

According to the study drug, we considered 2 groups of pts: group I pts treated with the sTNFR, group II pts treated with mAbanti-TNF (infliximab and adalimumab). Pts who failed for inefficacy (LaE or LoE) were respectively: 23 out of 174 and 32 out of 120 . The rate of failure was respectively: 0.05 vs 0.11 failure/pt/yrs (that means one 
withdrawal for inefficacy every 21.2 vs 9.5 $\mathrm{pt}$ /years respectively).

According to ILAR categories, pts who failed for inefficacy (LaE or LoE) were respectively 17 out of 50 with soJIA, 7 out of 28 seropositive polyarthritis, 11 out of 58 seronegative polyarthritis, 4 out of 50 persistent oligoarthritis, 12 out 87 extended oligoarthritis and 6 with other JIA. The rate of failure was respectively $0.14,0.11,0.07$, $0.03,0.05,0.06$ failure/pt/yrs.

In the multivariate analysis, the only predictor entered the final model, beside gender and kind of BT was the ILAR category. Pts treated firstly with $\mathrm{mAb}$-anti-TNF presented significantly higher failure rate (HR mAb-anti-TNF vs sTNFR 1.9, $\mathrm{P}=0.02$ ); about the ILAR category, pts with persistent and extended oligoarthritis presented significantly lower failure rate (HR persistent $v s$ soJIA $0.23, \mathrm{P}=0.01$ and $\mathrm{HR}$ extended vs soJIA $0.34, \mathrm{P}=0.008$ ).

\section{Discontinuation due to inactive disease/ remission}

According to gender, pts who stopped treatment do to the achievement of ID or CRM were 11 out of 217 females vs 16 out of 84 males. The rate of discontinuation for ID/CRM was respectively: 0.02 vs 0.07 ID-CRM/pt/yrs (that means one withdrawal for ID/CRM every 50.0 vs $15.1 \mathrm{pt} /$ years respectively).

According to diagnosis groups, pts who stopped treatment do to the achievement of ID or CRM were 4 out of 50 soJIA (8.0\%), 23 out of 251 non-soJIA (9.2\%). The frequency of discontinuation for ID-CRM was similar in both groups: 0.037 vs 0.039 discontinuation for ID-CRM/pt/yrs (that means one withdrawal for ID/CRM every 29.7 vs $29.5 \mathrm{pt} /$ years respectively).

According to study drug, pts who stopped treatment due to the achievement of ID or CRM were: 18 out of 174 treated with etanercept, 5 out of 83 treated with infliximab, 4 out of 37 treated with adalimumab. The rate of discontinuation for ID-CRM was similar in pts treated with subcutaneous biological drugs: 0.04 and 0.05 events/ $\mathrm{pt} / \mathrm{yrs}$ respectively with etanercept and with adalimumab (that means one withdrawal for ID/CRM every 27.1 vs $19.2 \mathrm{pt} /$ years respectively). The rate of discontinuation for ID-CRM in pts treated with infliximab was 0.02 events/pt/yrs (that means one withdrawal for ID/CRM every $45.5 \mathrm{pt} /$ yrs).

Table IV - Results from both the univariate and the multivariable models.

\begin{tabular}{|l|l|l|l|l|l|l|}
\hline \multirow{2}{*}{ Predictors } & \multicolumn{2}{|c|}{ Adverse events } & \multicolumn{2}{c|}{ Lack/loss of efficacy } & \multicolumn{2}{c|}{$\begin{array}{l}\text { Inactive disease or complete } \\
\text { remission }\end{array}$} \\
\hline & Unadjusted HR & Adjusted HR & Unadjusted HR & Adjusted HR & Unadjusted HR & Adjusted HR \\
\hline $\begin{array}{l}\text { Gender (M } \\
\text { vs F) }\end{array}$ & $\begin{array}{l}0.61 \\
(0.35-1.06)\end{array}$ & $\begin{array}{l}0.62 \\
(0.35-1.10)\end{array}$ & $\begin{array}{l}0.64 \\
(0.34-1.21)\end{array}$ & $\begin{array}{l}0.59 \\
(0.29-1.16)\end{array}$ & $4.07(1.9-8.69)$ & $\begin{array}{l}3.55 \\
(1.61-7.84)\end{array}$ \\
\hline $\begin{array}{l}\text { AntiTNF vs } \\
\text { Etanercept }\end{array}$ & $\begin{array}{l}1.37 \\
(0.87-2.16)\end{array}$ & $\begin{array}{l}1.12 \\
(0.69-1.82)\end{array}$ & $\begin{array}{l}2.05 \\
(1.20-3.5)\end{array}$ & $\begin{array}{l}1.90 \\
(1.08-3.35)\end{array}$ & $0.62(0.28-1.34)$ & $\begin{array}{l}1.00 \\
(0.44-2.27)\end{array}$ \\
\hline $\begin{array}{l}\text { Other vs } \\
\text { Etanercept }\end{array}$ & $\begin{array}{l}0.81 \\
(0.09-6.80)\end{array}$ & $\begin{array}{l}0.81 \\
(0.09-7.16)\end{array}$ & $\begin{array}{l}3.41 \\
(0.80-14.4)\end{array}$ & $\begin{array}{l}2.36 \\
(0.53-10.59)\end{array}$ & - & - \\
\hline $\begin{array}{l}\text { Disease } \\
\text { duration } \\
(5 \text { years) }\end{array}$ & $\begin{array}{l}1.19 \\
(0.56-2.52)\end{array}$ & $\begin{array}{l}1.17 \\
(1.16-1.18)\end{array}$ & $\begin{array}{l}1.09 \\
(0.51-2.32)\end{array}$ & - & $\begin{array}{l}0.605 \\
(0.60-0.61)\end{array}$ & $\begin{array}{l}0.65 \\
(0.645-0.655)\end{array}$ \\
\hline $\begin{array}{l}\text { OligoPer } \\
\text { vs Sys }\end{array}$ & $\begin{array}{l}0.85 \\
(0.40-1.77)\end{array}$ & - & $\begin{array}{l}0.24 \\
(0.08-0.73)\end{array}$ & $\begin{array}{l}0.23 \\
(0.08-0.73)\end{array}$ & $\begin{array}{l}1.06 \\
(0.24-4.67)\end{array}$ & - \\
\hline $\begin{array}{l}\text { OligoExt } \\
\text { vs Sys }\end{array}$ & $\begin{array}{l}1.31 \\
(0.74-2.33)\end{array}$ & - & $\begin{array}{l}0.36 \\
(0.17-0.75)\end{array}$ & $\begin{array}{l}0.34 \\
(0.15-0.76)\end{array}$ & $\begin{array}{l}0.94 \\
(0.27-3.30)\end{array}$ & - \\
\hline $\begin{array}{l}\text { PolyRFpos. } \\
\text { vs Sys }\end{array}$ & $\begin{array}{l}0.42 \\
(0.12-1.46)\end{array}$ & - & $\begin{array}{l}0.82 \\
(0.34-2.0)\end{array}$ & $\begin{array}{l}0.77 \\
(0.31-1.89)\end{array}$ & $\begin{array}{l}1.70 \\
(0.41-7.07)\end{array}$ & - \\
\hline $\begin{array}{l}\text { PolyRFneg. } \\
\text { vs Sys }\end{array}$ & $\begin{array}{l}0.95 \\
(0.48-1.87)\end{array}$ & - & $\begin{array}{l}0.52 \\
(0.24-1.14)\end{array}$ & $\begin{array}{l}0.56 \\
(0.24-1.28)\end{array}$ & $\begin{array}{l}1.87 \\
(0.58-5.99)\end{array}$ & - \\
\hline $\begin{array}{l}\text { Other } \\
\text { vs Sys }\end{array}$ & $\begin{array}{l}0.76 \\
(0.08-6.63)\end{array}$ & - & $\begin{array}{l}0.55 \\
(0.22-1.36)\end{array}$ & $\begin{array}{l}0.54 \\
(0.22-1.31)\end{array}$ & $\begin{array}{l}1.39 \\
(0.31-6.29)\end{array}$ & - \\
\hline
\end{tabular}


No pts treated with non-anti-TNF drugs during their first course discontinued due to disease control, and then were excluded when fitting multivariable model.

In the multivariate analysis the only predictor entered the final model for discontinuation due to inactive disease are, beside gender and BT, was disease duration. In particular, males (HR 3.5, $\mathrm{P}=0.002$ ) and pts with shorter disease duration before starting BT shows higher remission rate (HR for $5 \mathrm{yrs}$ $1.54, \mathrm{P}=0.05$ ).

Results from both the univariate and the multivariable models were summarized in Table IV.

\section{DISCUSSION}

Since the beginning of 2000 , on the basis of controlled trials that proved the efficacy and safety of TNF $\alpha$ blockade in JIA, this therapeutical approach has been extensively applied in clinical practice. Biologics have revolutionized the treatment of JIA due to their efficacy, speed of onset and tolerability. Overall tolerability of anti-TNF $\alpha$ therapy in JIA was good in ours $(1,10)$ as in many other studies, but data on their longterm efficacy and safety remain relatively scarce. There have been few reports of BT discontinuation rates and factors associated with discontinuation (2-4). The aim of this study is to collect long-term outcome data on children receiving biological agents for JIA in terms of drug survival and to explore the reasons for biological therapy discontinuation.

Our cohort of 301 pts treated with BT represents the more severe spectrum of JIA, those who failed to tolerate or respond to MTX and previous DMARDs and suffering from long lasting disease.

Drug survival data from this 10-year-follow up study, in a real-life setting of unselected population, proves that more than $50 \%$ of pts continue the treatment at 36 months, suggesting that the majority of them find biological drug tolerable and effective. Different drug survival data have been reported by etanercept European registries (2-4, 11). Nevertheless, due to the difference in patients' numbers, duration of follow-up, and drug administered, a comparison with the European registries is difficult.

The majority of pts who suspended the $1^{\text {st }}$ biological approach for any reason (120/165) switched to a second biological treatment, more frequently a further TNF- $\alpha$ blocking agent.

The most common reasons for stopping BT in our cohort were AEs. It is interesting that infusion reactions have been the most frequently reported AEs but infliximab therapy was not a predictor of discontinuation for AEs. Data from Finnish registry (4) showed that infliximab was more often discontinued because of AEs, even if, overall treatment survival of etanercept and infliximab in JIA was comparable. In our study a significant lower chance to stop due to AEs was observed in patients with shorter disease duration before starting BT, moderate evidence was also found for male gender. In all the European cohorts $(2-4,12)$ systemic JIA has been previously reported to be associated with etanercept inefficacy. Also in our study the probability of discontinuation for inefficacy (lack or loss of efficacy) was associated with systemic JIA. Furthermore, in our study, the probability of discontinuation for inefficacy was associated with the use of mAb anti-TNF $v s$ sTNFR.

Our results, based on a large number of pts, showed that only few patients (\#27) suspended for disease control. Nevertheless, 136 of our pts reached the CRM but in the majority of them, according to our clinical approach/judgment, to avoid a possible relapse, we preferred to maintain a long lasting treatment. Indeed half of patients (13/27), who stopped for ID, restarted therapy because of relapse of disease after a median period free from biological drug of 6.6 months. Male gender and earlier initiation of BT increased the chance to reach ID/CRM and to stop the treatment for this reason. This has been already observed in other European cohorts (11), therefore we suggest that an effective BT should be offered within a narrow time period from the disease onset. No statistically difference was found between ILAR subtypes. 
In conclusion, while the study confirms that BT is globally well tolerate and effective in JIA, the probability to withdrawal for disease control is low and associated with shorter disease duration at the beginning of treatment. However, the prolonged use of BT provides objective surrogate information of clinical benefit during first biological course.

\section{Conference presentation: XLIX SIR Na-} tional Congress, Milano, 2012.

Conflict of interests: the authors declare no potential conflict of interests.

\section{REFERENCES}

1. Gerloni V, Pontikaki I, Gattinara M, Fantini F. Focus on adverse events of tumour necrosis factor $\alpha$ blockade in juvenile idiopathic arthritis in an open monocentric long-term prospective study of 163 patients. Ann Rheum Dis. 2008; 67: 1145-52.

2. Horneff G, Schmeling H, Biedermann T, Foeldvari I, Ganser G, Girschick HJ, et al. The German etanercept registry for treatment of juvenile idiopathic arthritis. Ann Rheum Dis. 2004; 63: 1638-44.

3. Prince FH, Twilt M, ten Cate R, van Rossum MA, Armbrust W, Hoppenreijs EP, et al. Long-term follow-up on effectiveness and safety register of etanercept in juvenile idio- pathic arthritis; the Dutch national register. Ann Rheum Dis. 2009; 68: 635-41.

4. Tynjälä $P$, Vähäsalo $P$, Honkanen V, Lahdenne $P$. Drug survival of the first and second course of anti-TNF agents in juvenile idiopathic arthritis. Ann Rheum Dis. 2009; 68: 552-7.

5. Giannini EH, Ruperto N, Ravelli A, Lovell DJ, Felson DT, Martini A. Preliminary definition of Improvement in juvenile arthritis. Arthritis Rheum. 1997; 40: 1202-9.

6. Wallace C, Ruperto N, Giannini EH. Preliminary criteria for clinical remission for select categories of juvenile idiopathic arthritis. J Rheumatol. 2004; 31: 2290-4.

7. Marubini E, Valsecchi MG. Analyzing survival data from clinical trials and observational studies. Chichester: Wile 1995; 10.3-10.10.

8. Fine JP, Gray RJ. A proportional hazards model for the subdistribution of a competing risk. JASA 1999; 94: 496-509.

9. Schemper M, Smith TL. A note on quantifying follow-up in studies of failure time. Control. Clin. Trials 1996; 17: 343-6.

10. Pontikaki I, Gerloni V, Gattinara M, Luriati A, Salmaso A, De Marco G, et al. Side effects of anti-TNFalpha therapy in juvenile idiopathic arthritis. Reumatismo 2006; 58: 31-8. [In Italian].

11. Papsdorf V, Horneff G. Complete control of disease activity and remission induced by treatment with etanercept in juvenile idiopathic arthritis. Rheumatology (Oxford) 2011; 50: 214-21.

12. Southwood TR, Foster HE, Davidson JE, Hyrich KL, Cotter CB, Wedderburn LR, et al. Duration of etanercept treatment and reasons for discontinuation in a cohort of juvenile idiopathic arthritis patients. Rheumatology (Oxford) $2011 ; 50: 189-95$. 